\title{
Presas' de una rehabilitación que no pidieron
}

\author{
Preys of a rehabilitation who did not ask
}

La invención puede y debe ser obra de todos ${ }^{2}$

MaUd Mannoni

\begin{abstract}
Resumen
Revisión de prácticas institucionales dentro de un centro de día que presta servicios a personas adultas con discapacidad intelectual, con extensas y generalizadas necesidades de apoyo, especialmente, pero no únicamente, en la comunicación, y que está implementando los principios de la Convención sobre los Derechos de las Personas con Discapacidad. Se recorren diversas situaciones que evidencian cómo subsisten prácticas de exclusión, reproducción de estructuras de poder, principalmente la subsistencia de la infantilización y seudoadultez. Se cruzaran prácticas con postulaciones teóricas y propuestas de autovigilancia tendientes a visibilizar procesos intrainstitucionales, con especial interés en la posición pasiva de los usuarios en relación con el sistema de rehabilitación, dificultades en promover la plena participación y propuesta de mejores intervenciones.
\end{abstract}

\section{Palabras clave}

Personas con discapacidad intelectual, organización no gubernamental, centros de rehabilitación, cuidadores, derechos y libertades.

\begin{abstract}
Review of institutional practices within a day center that provides services to adults with intellectual disabilities, with extensive and widespread support needs, especially, but not only, in communication, and that is implementing the principles of the Convention on the Rights of Persons with Disabilities. Various situations are analyzed that show how practices of exclusion persist, reproduction of power structures, mainly the subsistence of infantilization and pseudo-adulthood. Practices will be crossed with theoretical postulates and self-monitoring proposals tending to make intra-institutional processes visible, with special interest in the passive position of users in relation to the rehabilitation system, difficulties in promoting full participation and proposals for better interventions.
\end{abstract}

\section{Keywords}

People with intellectual disabilities, non-governmental organization, rehabilitation centers, caregivers, rights and freedoms.

1. Al pensar el título se utilizó la palabra 'Presos'. Al buscar una forma que contemple la perspectiva de género, se decide utilizar 'Presas', porque implica múltiples significados: personas, animales o cosas que resultan cazados, robados o atrapados, especialmente si es con violencia o lucha.

2. No se confunda quien lea pensando que encontrará un tratado de psicoanálisis dada la cita del comienzo. Piénsese más como una referencia literaria que tiene relevancia para quienes escriben por estar transitándose una experiencia de vivienda convivencial y por otras razones que irán apareciendo.

\section{Karina Guerschberg $<$ karinaguers@gmail.com> \\ Asociación Civil Senderos del Sembrador. Argentina}

\section{Gustavo Rubinowicz <grubinowicz@yahoo.com.ar>}

Asociación Civil Senderos del Sembrador. Argentina

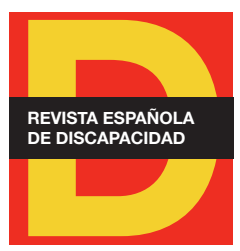

Para citar:

Guerschberg, K. y Rubinowicz, G. (2019): "Presas de una rehabilitación que no pidieron". Revista Española de Discapacidad, 7 (I): 111-132.

Doi: <https://doi.org/10.5569/23405104.07.01.06>

Fecha de recepción: 15-02-2018 Fecha de aceptación: 20-02-2019

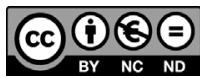




\section{Introducción}

En el siguiente artículo reflexionaremos sobre las prácticas profesionales en un centro de día que presta servicios a personas adultas con discapacidad intelectual, con extensas y generalizadas necesidades de apoyo, especialmente, aunque no únicamente, en la comunicación, y que se encuentra atravesando un proceso de transformación organizacional hacia una institución centrada en el usuario ${ }^{3}$. Cómo es necesario e imperioso discutir y criticar los conceptos profesionales adquiridos en la formación o en la práctica en otras organizaciones, e incluso en la misma organización ${ }^{4}$ que nos ocupa, previo a este cambio teórico-ético.

Como somos conscientes de no ser los primeros en cuestionar las prácticas, y efectivamente haremos referencia a textos y posturas que tienen 40 años o más, proponemos a quien lee un ejercicio de autovigilancia, el mismo que nos planteamos a nosotras y nosotros mismos en nuestra práctica profesional. El desafío de encontrarse ya no en las coincidencias teóricas, que posiblemente compartiremos, sino en las prácticas que aún reproducen la exclusión, la asimetría en las relaciones usuario/profesional. Los profesionales somos tanto parte del problema como parte de la solución. Desde el momento en que decidimos participar en los procesos de facilitación, estamos "en el problema". No somos personas que observan ajenas y asépticas.

Estamos atravesando un proceso donde lo que hicimos siempre ahora resulta incorrecto, desajustado o violento, aunque a veces no podemos verlo. Al abandonar la posición del 'saber' nos enfrentamos a la angustia del no saber, al dolor de empatizar con ese otro que es más igual de lo teorizado hasta entonces. Hacemos este escrito porque partimos de la suposición de que necesitamos fortalecer la co-construcción, la acción conjunta intrainstitucional de un engranaje (usuario/profesional) permeable, débil, donde la disparidad y las interrupciones en lo dialógico son absolutamente posibles en lo cotidiano.

Entendemos que las y los usuarios deben empoderarse para ejercer sus derechos, pero la paradoja es que para que ello ocurra debemos virar la atención hacia la práctica de los profesionales y personal de la institución. Hacia este lugar estamos mirando al escribir este artículo, el cual representa el devenir diario del centro.

3. En este trabajo se ha tratado de utilizar un lenguaje sensible al género, pero el caso de la palabra 'usuario' ha representado un desafío difícil de superar. Hemos intentado en cada caso hacerlo lo más ajustado posible, pero para no sobrecargar la lectura encontrarán que se ha usado en forma alternada. No estamos conformes con la elección y queremos aclarar que cada vez que se encuentren con esa palabra estamos haciendo referencia a usuarias y usuarios.

4. Para ampliar sobre el proceso de transformación profesional sugerimos el artículo "Hacia una institución centrada en la persona" de Brea et al. (2016) <https://docs.google.com/document/d/1aOtCcY1gLLODxNo1VgvssIBW4Go_LbiocxoglmnC5Ik/edit?usp=sharing> y "Del dicho al hecho: hacia un centro de día centrado en las personas" de Brea et al. (2017) <https://docs.google.com/document/d/17CviHosG2G0FVpvULjtmqqig6vs_ MxgsLnbslYmBzpl/edit?usp=sharing>. 


\section{Sobre la metodología ${ }^{5}$}

Iniciamos este texto con el objetivo de mostrar la complejidad de la práctica de una institución que pretende ser centrada en el usuario.

Creemos que para que esto sea posible se necesitan profesionales reflexivos y no solo ejecutantes, dispuestos a mantener un diálogo abierto con personas con evidentes dificultades para conversar. Pensamos como Bakhtin $(1981,1984)$ que las palabras no son nunca solamente nuestras sino que nos llegan cargadas de significados y formas en las que las personas las utilizan, y a la vez pueden ser utilizadas en diversas formas cuando se conversa. "Vivir significa participar en diálogo..." (Bakhtin, 1984: 293).

Para poder promover ese diálogo trabajamos desde la perspectiva de las prácticas dialógicas colaborativas, que proponen una forma diferente de conceptualizar el conocimiento y la investigación, desafiando algunos mitos e ideas como que la investigación es un proceso científico que sólo puede ser ejecutado por investigadores que tengan una formación específica, enfocada en un objeto externo, donde el investigador debe ser objetivo y neutral, que debe ocurrir después del hecho, utilizando un método validado y confiable, que debe poder ser repetible y sus resultados generalizables (Anderson, 2017) De la serie de mitos que se señalan, a los efectos de este artículo nos interesan especialmente dos puntos: la validación de la recolección de datos y la investigación ocurriendo después del suceso. Siguiendo a Anderson afirmamos que las prácticas dialógicas colaborativas en las que enmarcamos nuestro trabajo nos involucran como profesionales que reflexionan en la acción: reflexionar, detenernos y repensar sobre nuestro andamiaje teórico, y describir nuestras prácticas. Así la teoría influencia la práctica y la práctica produce teoría. Es dentro de estos conceptos teóricos que escribimos el artículo.

Se reflexiona sobre los diálogos sucedidos dentro de un centro de día ${ }^{6}$, en Argentina, que presta servicio a 30 adultos con discapacidad intelectual de entre 25 y 50 años, con extensas o generalizadas necesidades de apoyo especialmente en la comunicación. La forma de trabajo es la sistematización de la observación de las diversas situaciones en las que estamos inmersos día a día y la reflexión que la acompaña. Durante las prácticas utilizamos todo tipo de registros incluyendo notas, grabaciones de audio, videos. Los mismos se comparten entre los profesionales y usuarios, con instancia de reflexión en equipo inspirados en el concepto de equipo reflexivo (Andersen, 1993). Los talleres son filmados y ese material se comparte con familias quedando como un testimonio al que todos podemos acceder para volver a ver, para ser un recordatorio que apoye a otros diálogos de la vida institucional. Los videos son también transformados en otros formatos, por ejemplo en una grilla, en pictogramas, en textos, adaptados al usuario y sus modos de comunicación. Las reflexiones que surgen de estos intercambios se registran en cuadernos de campo y luego se procesan en formatos de textos de reflexión, como el presente artículo. En la investigación dialógica, la reflexión crítica, el avance en un conocimiento para la acción transformadora, se genera en el cruce de voces, sin que ninguna de ellas tenga privilegios sobre las otras (Valencia, 2016).

5. Este capítulo se desarrolló en función del proceso de evaluación del artículo, donde se nos sugirió explicitar la metodología utilizada. Agradecemos la oportunidad de poder fundamentar metodológica y teóricamente el trabajo pero al ser una forma no tan difundida, seguramente no alcance. Nos ponemos a disposición de los lectores para ampliar y responder consultas al respecto.

6. Para más datos sobre el centro de día Senderos del Sembrador sugerimos visitar la web http://asociacionsenderos.org.ar/. 
Este reflexionar en acción nos permite tener nuevas ideas y generar conocimiento con mayor profundidad, como señala Shotter (1993) "performative understanding"7 (comprensión performativa). La investigación dentro de las prácticas dialógicas colaborativas rompe la dicotomía investigador/objeto proponiendo al investigador como participante de una relación, donde es influenciado por los otros, y cada uno de los participantes contribuye al resultado. Se convierte en un proceso descentralizado de aprendizaje, donde quienes antes podían ser vistos como objeto de estudio son considerados participantes en una relación de aprendizaje mutuo (Anderson, 2018) En este trabajo debe esperarse entonces encontrar reflexiones de los participantes, preguntas hechas en el contexto y en el texto (Pakman, 2014) de la práctica misma. No se habla de los otros, sus textos y sus contextos, como señala Ghiso (2009), sino con los otros, con sus textos y con sus contextos. Una investigación basada en "espacios de encuentro donde la pregunta y el versar colectivo se erigen en posibilidad para recuperar, tener y usar la propia voz en medio de formas de poder, tensiones y diferencias" (Valencia, 2016).

Investigamos mientras ejercemos nuestras funciones profesionales, aprendemos de la teoría pero a la vez la ponemos en cuestión, tanto entre los profesionales como en conjunto con los usuarios y sus familias, y vamos desarrollando diferentes abordajes, que a la vez nos impulsan a nuevas reflexiones. Procesos que lejos de ser circulares y escalonados, son simultáneos y constantes. Nos consideramos coinvestigadores con las familias y usuarios, y nuestro "objeto de estudio" son las mejores prácticas en función de los objetivos de aquellos para los que trabajamos.

Nos interesa particularmente reflejar la importancia de la utilización del lenguaje en los contextos de abordaje profesional de personas en situación de discapacidad, dado que consideramos a las personas como seres sociales de diálogo relacional (Bakhtin, 1986; Wittgenstein, 1953) y el conocimiento como una actividad social interactiva de las personas, donde se genera nuevo conocimiento por medio de la investigación mutua, la exploración conjunta con énfasis en la comunicación.

\section{Qué profesionales necesitamos}

Nos encontramos en una situación donde las personas con discapacidad están infantilizadas y sobreprotegidas, cautivas de un sistema rehabilitatorio. Profesionales formados en un modelo médico. Una sociedad prejuiciosa y segregada, capacitista. Pensamos como Fricker que una disfunción prejuiciosa de la práctica testimonial puede ser de dos tipos: un "prejuicio que se deriva de que se otorgue a la hablante más credibilidad de la que se le otorgaría en otras condiciones (un exceso de credibilidad) o bien se deriva de que se le otorgue menos credibilidad de la que recibiría en otras condiciones" (un déficit de credibilidad) (Fricker, 2017: 38).

Esperamos aportar a la reflexión para la modificación de las prácticas profesionales en los servicios de discapacidad, en especial, el que nos aloja.

7. Mantenemos el original en inglés para que el lector discuta o no nuestra traducción de la expresión. 
Figura 1. Mapa conceptual sobre el objetivo, perfil profesional y punto de partida para gestionar el cambio de una institución hacia un modelo centrado en la persona

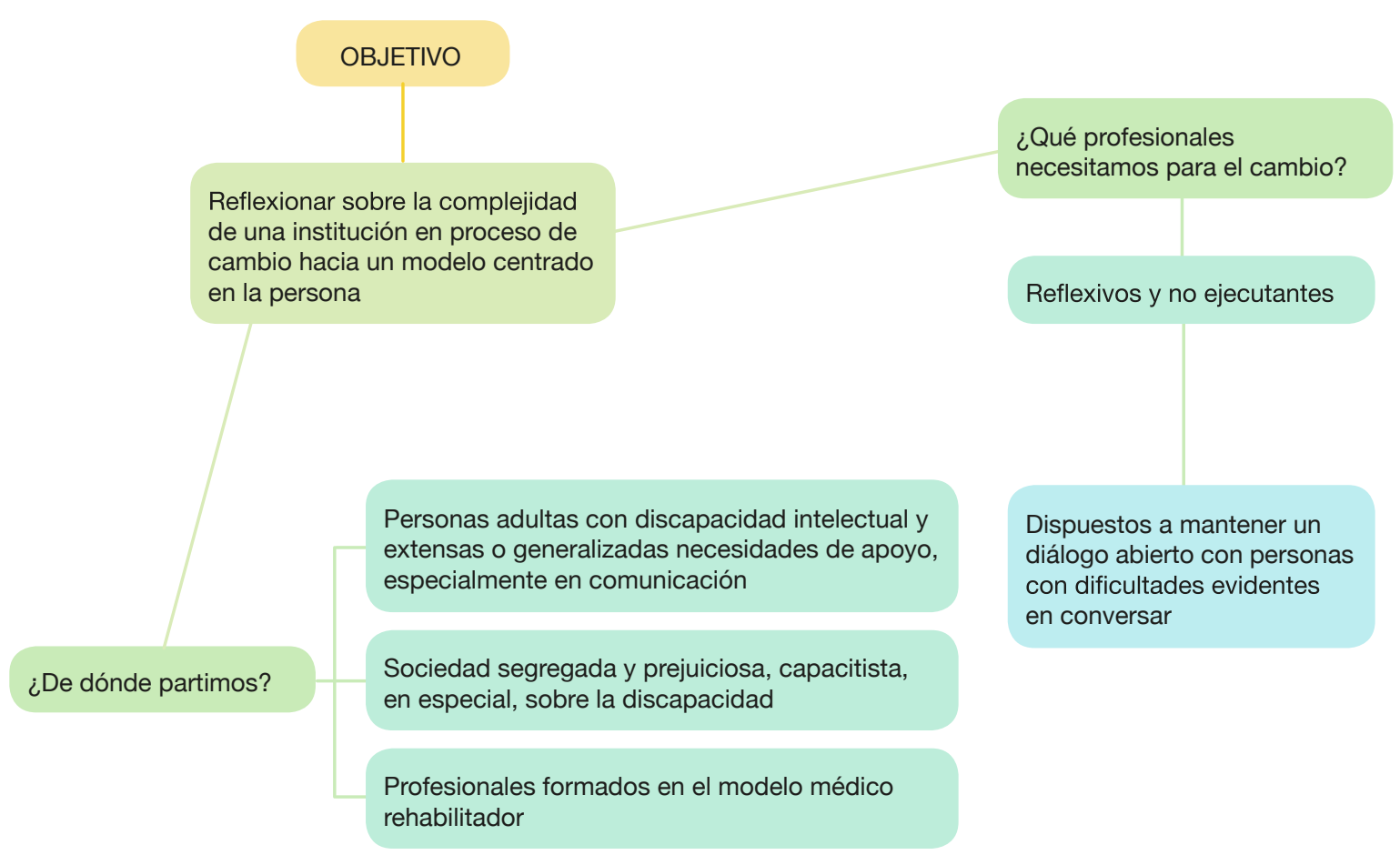

Fuente: elaboración propia.

\section{Ser personas adultas}

"Las causas que originan la discapacidad no son ni religiosas ni científicas, sino (...) preponderantemente sociales. (...) no son las limitaciones individuales las raíces del problema, sino las limitaciones de la propia sociedad, para prestar servicios apropiados y para asegurar adecuadamente que las necesidades de las personas con discapacidad sean tenidas en cuenta"

(Palacios, 2008: 103-104).

Las personas con las que trabajamos son adultas con extensas o generalizadas necesidades de apoyo. Son personas con discapacidad. Partimos de un acuerdo respecto de la definición y conceptualización de la discapacidad como fenómeno social y en la necesidad de desarrollar servicios adecuados. Sin embargo, en la práctica cotidiana nos encontramos que en las conductas del personal del centro se refleja cómo subsisten o quizás cómo se develan las creencias colectivas, los prejuicios sobre la discapacidad. 
Muchas prácticas se sostienen como forma de protección. Como señala Montobbio (1995: 27) "Para impedir que se enfrente al sufrimiento y el fracaso, se le evitan momentos que hacen posible la prueba, el enfrentamiento con sus propias capacidades y también con sus propios límites". Así la sobreprotección aparece como uno de los primeros obstáculos para el desarrollo de un "ser adulto" verdadero.

La intención es buena, pero con malas consecuencias. Se perpetúan los comportamientos infantiles donde otra persona adulta "asume las tareas que se supone que la persona con diversidad funcional no será capaz de llevar a cabo con éxito, y la toma de decisiones sobre la propia vida de la persona" (Diez Muñio, 2017: 27). Esta infantilización se construye al referirse a la persona con discapacidad como un niño o niña, utilizando diminutivos, elogiando en exceso, hablándoles de modo demasiado afectuoso. Este hecho es habitual tanto en las instituciones especializadas como en las familias (Cardona, 2006).

Los profesionales parecen estar formateados para desestimar las opiniones de las personas con discapacidad intelectual, basados en la idea que como el déficit es cognitivo sus opiniones son menos válidas. Podríamos pensar que se trata de una forma de injusticia epistémica, que "consiste en causar un mal a alguien en su condición específica de sujeto de conocimiento" (Fricker, 2017:13). Y podemos observar los dos tipos de injusticias que la autora describe: injusticia testimonial, que es la que "se produce cuando los prejuicios llevan a un oyente a otorgar a las palabras de un hablante un grado de credibilidad disminuido", y la injusticia hermenéutica, que es una actitud previa, donde "una brecha en los recursos de interpretación colectivos sitúa a alguien en una desventaja injusta en lo relativo a la comprensión de sus experiencias sociales" (Fricker, 2017: 13).

En el desarrollo de este trabajo se nos planteó como dificultad la forma de nombrar profesionales y usuarios/ as, ambos adultos, para poder distinguir cuando aparece esta idea de seudoadultez reflejada en las prácticas.

Todas las personas dentro del centro de día son adultos y adultas, pero no todas se consideran, sienten o son reconocidas como tales.

\section{Los caprichos de las personas adultas}

"Las personas alrededor del mundo cada vez más necesitan ser escuchadas respecto de las decisiones que afectan sus vidas: qué clases de servicios necesitan, y cómo esos servicios les son provistos.

Piden un mundo más igualitario donde sean respetadas como personas que se conocen a sí mismas, sus vidas, circunstancias y requerimientos, mejor que un extraño" Harlene Anderson (2017: 1).

Las reflexiones que a continuación compartimos surgen de situaciones concretas. Llevamos registro sistemático de situaciones conflictivas y las reflexiones posteriores que se desarrollan dentro del equipo profesional 
como se explicó al comienzo. Elegimos para el relato reproducir partes de la escena, ocupados en no violar la privacidad de quienes participan. $Y$ en vez de utilizar una viñeta de relato, darle un formato de esquema.

A: usuario o usuaria del servicio, persona adulta con discapacidad intelectual.

B: profesional, facilitador o facilitadora.

C: supervisora o supervisor.

D: practicante, persona con rol de observación.

Una persona adulta (A) grita porque en medio de la actividad desea maquillarse, algo que nada tiene que ver con lo que quien ejerce el rol de facilitación (B) tiene planificado como actividad. Este profesional (que es una de las personas adultas participantes de ese evento) dice que es un "capricho's, sentenciando como no válida la demanda de A. B enuncia entonces una "verdad', su verdad. No hay un deseo, no hay algo potencialmente novedoso, ni una banalidad, hay un capricho.

Esa verdad es expresada y pensada con tanto énfasis (gritos, llantos, reproches ampulosos, descrédito) que A llora y ese llorar se convierte desde el decir de B en más capricho, en confirmación de su verdad.

Dijimos que necesitamos profesionales más reflexivos, y nos preguntamos ¿lo dejará tranquilo/a, cómodo/a, haber "logrado imponer" su verdad?, ¿qué se dirá para sus adentros respecto a "ese logro"?, ¿se preguntará algo al respecto?, ¿cómo repercute en los otros usuarios testigos del evento?, ¿cómo rebota ello en las paredes institucionales?

La fórmula sería:

Figura 2. Esquema de la relación entre el llanto de A (persona con discapacidad y la sentencia (capricho) de B (profesional)

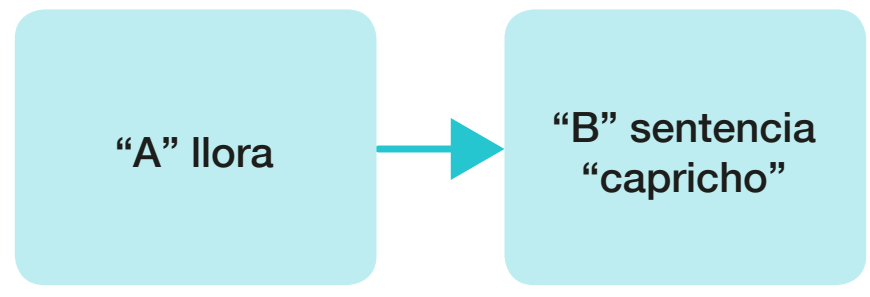

Fuente: elaboración propia.

Pensemos en la palabra 'capricho': cuando alguien define el comportamiento de otra persona (en este caso las personas usuarias) como 'caprichoso/a' no refiere solo a un pensamiento aislado, a una palabra inade-

8. Del it. capriccio. 1. m. Determinación que se toma arbitrariamente, inspirada por un antojo, por humor o por deleite en lo extravagante y original (definición RAE: http://dle.rae.es/srv/search?m=30\&w=capricho). 
cuada que se escapó en ese momento. Son conceptualizaciones históricas que flotan en los ambientes relacionados a instituciones que trabajan con la discapacidad y que aparecen en momentos determinados como una condensación y evidenciación de aquello antes pensado.

En este caso el profesional es el ejecutante de decir en voz alta una palabra (capricho) que le pertenece no solo a él sino a un sistema de pensamiento biopolítico tan establecido que no se necesita hacer demasiada fuerza para ejecutarlo y que el usuario "lo acepte". Por ejemplo: siéntate, anda para allá, etc. El profesional está 'alineado' como señala Fricker, a un tipo de coordinación más específica que constituye la 'alineación' social necesaria de la que toda relación de poder dada depende directamente. Esta "alineación social es en parte constitutiva de la relación de poder" (Fricker, 2017: 29)

Dice Paul Veyne (2014: 105) citando a Focault: “...es un hecho que, sin que previamente se ejerza ninguna violencia sobre ella, la gente se ajusta a unas reglas, sigue unas costumbres que le parecen evidentes". $Y$ luego agrega: "El poder consiste en la capacidad de conducir no físicamente las conductas del otro".

Remata diciendo: "somos libres, cuando podemos ofrecer de alguna manera menor a mayor Resistencia". Lo que hacen las y los usuarios en ciertas ocasiones es ofrecer resistencia. Esa resistencia es leída como un acto de libertad en algunas ocasiones y conceptualizada como desajuste, falta de respeto, empeoramiento del síntoma, etc., en otras. El trabajo institucional no consiste en darle la razón a una de las partes sino hacer evidente a los procesos recién mencionados en los que se suceden estos eventos.

Ahora, además, hay que evitar que el capricho se convierta en mecanismo para obtener lo que quiere.

Viñeta: una tercera persona, C (profesional supervisor), interviene e interrumpe el 'reto', pregunta qué está pidiendo la persona que llora, y se lo facilita.

A llora, B sentencia, C valida el reclamo de A, B dice que ahora A aprendió un mecanismo para obtener lo que desea.

Según B, la persona debe someterse al decir del profesional, quien puede determinar qué demanda es válida, qué deseo es posible o aceptable. La persona debe ser dócil.

Pero B se angustia con la intervención y C propone una reflexión sobre la situación: "Si A pudiera daría un portazo, o nos mandaría a la mierda, pero está presa de un sistema que no eligió" como el intento de hacer evidente el funcionamiento de esa danza del ejercicio del poder, para torcerle el brazo a esas prácticas clasificatorias ejercidas por los profesionales y empoderar el ejercicio de la resistencia de las y los usuarios.

Dice Pakman (2010), que este modo de control y domesticación se basa en el conocimiento como tecnología positiva extendida en lo social, colonizando lo cotidiano de los sujetos libres. Se encarna en el mecanismo esencial de un poder de normalización y que en la práctica clasificatoria se extiende, y los expertos de la salud mental se van volviendo maestros en decidir sobre la normalidad de la gente.

Un equipo profesional que supuestamente promueve los derechos consagrados en la Convención sobre los Derechos de las Personas con Discapacidad, que propone objetivos de trabajo dentro del modelo de Cali- 
dad de Vida (Verdugo, 2009) pero que parece esperar de los usuarios y usuarias docilidad y obediencia. EI poder busca reproducirse dentro de la organización, acentuando la diferencia entre quienes ocupan el rol de usuarios y profesionales.

Según Foucault (1976: 182) el poder "no pesa solamente como una fuerza que dice no, sino que de hecho la atraviesa, produce cosas, induce placer, forma saber, produce discursos; es preciso considerarlo como una red productiva que atraviesa todo el cuerpo social más que como una instancia negativa que tiene como función reprimir".

Por eso no extraña que el sometimiento pueda ser pasivo y por ello pasar inadvertido e incluso descrito como buena conducta, amabilidad o cualquier tipo de connotación positiva. O puede ser tormentoso, en donde el usuario (tal vez sin saberlo o sin poder enunciarlo como una queja/demanda) "se desajusta" y no accede a cumplir con determinada orden. No por no volitivo, no por no meta-conceptualizado deja de ser esa una voz que nos convoca a actuar, a estar alertas, a repensar la práctica.

Figura 3. Mapa conceptual sobre la propuesta de perfil de profesionales necesarios para el cambio

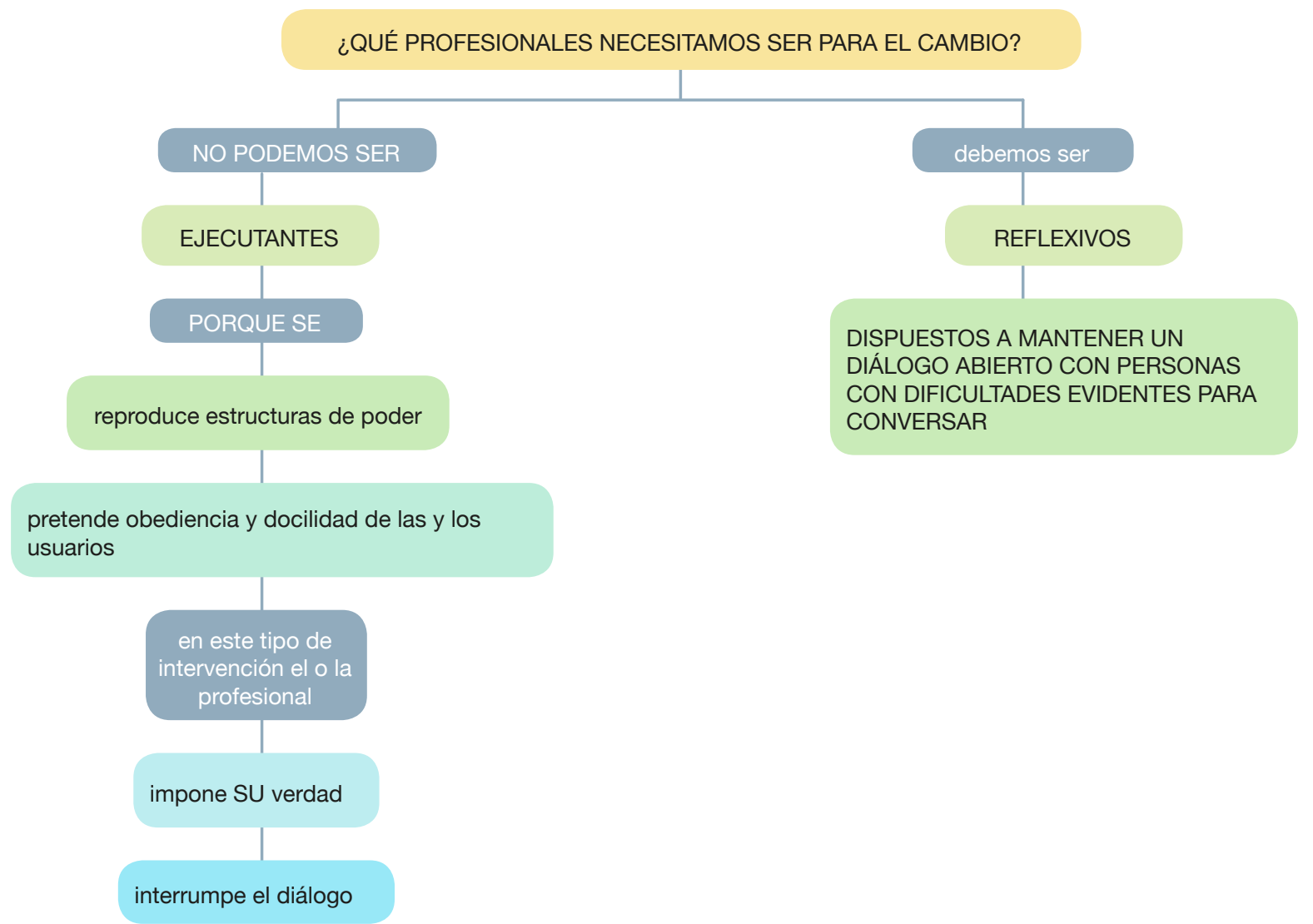

Fuente: elaboración propia. 


\section{Las reglas del juego}

Pensamos como Gergen (2009) que para comunicarnos usamos el lenguaje de acuerdo a reglas preestablecidas por el contexto y en función de la relación interpersonal. En el caso que presentamos, las y los usuarios no saben jugar con las reglas establecidas para "hacer su pedido". Este "no saber jugar" no es sólo producto del déficit cognitivo, sino de una suma de factores preexistentes incluyendo aislamiento, infantilización, pobreza en el intercambio lingüístico; y tampoco conoce los mecanismos para confrontar con "la verdad" del profesional. El estado emocional de ese momento es el desamparo. No se tiene a una o uno mismo y tampoco la o el acompañante que le ha designado la vida institucional para que colabore con aquellos deseos. Además de tener que vérselas con sus propias dificultades, "debería aprender" a comportarse con las reglas simbólicas de su profesor, psicólogo, etc.

Preguntamos nuevamente: ¿el o la profesional que impuso su verdad, quedó conforme?

Cuando se expresa esa verdad, quién lo hace se posiciona instantáneamente en un lugar de poder unidireccional y exactamente en ese momento se esfuma la idea de la institución centrada en la persona. "El saber -la ilusión de entender, o la seguridad de un método- reduce la posibilidad de ver, y empeora nuestra sordera sobre lo inesperado, lo no dicho y lo todavía no dicho" (Anderson y Goolishian, 1988:186).

La agresión a la que se está sometiendo a la persona es transparente, porque es tangible, pero no puede verse. Una violencia sin intención, pero no por eso menos violenta. Si pudiera daría un portazo, o nos mandaría a la mierda, pero está presa de un sistema que no eligió. Un disciplinamiento carcelario, sin rejas ni libertad condicional. La violencia es silenciosa aunque sea ejecutada "a los gritos" porque no sabemos, no percibimos cómo le afecta al usuario, ni al profesional, ni a los testigos institucionales lo ocurrido; pero sí sabemos que ha ocurrido.

En la vida institucional estamos especialmente atentos a intervenir "en vivo" y luego en diferido en todos los eventos en donde se invisibilice la agresión (no nos referimos a violencia física sino a destratos, desestimar demandas, interrupción del diálogo que convierte la relación en víctima-victimario) y se normalicen vínculos desajustados entre usuarios y profesionales.

Diversas son las y los actores que participan en la escena. Víctimas, victimarios (aunque hayan deseado obrar bien, han sido agentes de la violencia) y testigos. En el modelo organizacional que proponemos no es posible apelar inocencia. Las y los testigos deben intervenir para promover un diálogo profundo y respetuoso.

7. Una conversación que se vuelve militancia

Otra cosa que se interrumpe en este intento de domesticación de quienes ocupan el rol de usuarios es la conversación. Ya no hay mutualidad hay solo soliloquios (de los usuarios y de los profesionales). Ya no se habla con el otro. Se habla para sí mismo y para las y los otros profesionales. 
En un dispositivo centrado en el usuario en el actual contexto, practicantes y profesionales deben comprender que no están simplemente trabajando o estudiando, están desarrollando acciones de militancia, donde sus actos deben garantizar que el usuario obtenga los apoyos que necesita para desarrollar su proyecto de vida y ejercer los derechos, pero a la vez ser conscientes de que están impactando sobre la percepción de la discapacidad que tiene otros profesionales, la familia, la sociedad, y él o ella misma.

Por otro lado, desde esta nueva mirada, la persona con la que 'trabajo' es un par, es un semejante. Se ponen en juego procesos de identificación que ponen de relevancia que este semejante está en situación de desigualdad. Y me genera angustia pensar que si tomo decisiones sobre el otro lo que estoy haciendo es violento, invasivo, tirano. Se vuelve imperioso pensar que yo con el otro tengo una sociedad. Que hay que ponerse de acuerdo. En esta construcción de proyecto en sociedad, el profesional tiene que aceptar resignar su propio deseo, sus propios intereses, para que esa sociedad sea posible.

Es en el concepto militancia que podríamos encontrar una referencia a un estilo de vida, y por consiguiente debemos elegir entre todo y nada. No se puede ser un poco atento y respetuoso con los deseos del otro. Las acciones de militancia a las que nos referimos nos requieren de por vida una práctica de análisis del propio accionar y del de los demás en pos de lograr que la brecha que existe entre las personas con y sin discapacidad intelectual debido a la desigualdad de oportunidades se acorten cada vez más, no solo entre el usuario y el profesional sino entre la persona y la sociedad en la que se encuentra a la vez inmersa y excluida?

El énfasis en la conversación intenta disminuir la injusticia epistémica, desacreditando lo que alguien tiene que decir, basado en prejuicios y más específicamente, una injusticia hermenéutica, dado que lo que aquí está desacreditado es la voz del colectivo de personas con discapacidad intelectual, asignándoles falta de recursos interpretativos, y por tanto, incapacidad para relatar su propia experiencia (Fricker, 2017).

\section{Sobre la comodidad de las frases hechas}

Dos de los usuarios se ponen de novios. Se besan. Quienes se besan son evaluados. ¿Se besan en exceso?, ¿se besan con corrección?, ¿se besan en consenso? Antes decíamos "acá no" y poníamos la institución como límite. "Esas cosas no son para acá", aunque siempre supimos que no había otro lugar. Que si no era acá, simplemente no era. Pero mejor no pensar. Porque empatizar con estos 'otros' cuya sexualidad es negada y renegada, imaginarse una vida sin sexo, resulta en extremo perturbador. Y es más fácil, más cómodo, pensar que "acá no". Como señala Foucault (2007: 12) "bien se sostiene este discurso sobre la moderna represión del sexo. Sin duda porque es fácil de sostener".

Y entonces, cuando "acá si" la incomodidad de los profesionales escala. Y piden nuevas normas, nuevas reglas. Quieren recuperar el poder de definir qué, cómo, cuánto y con quién. Mirar estos 'otros' inquieta. Estos 'otros' que se niegan a ser dóciles.

9. Este párrafo es colaboración con Milagros Albornoz Orfila. 
Aquí aparecen con fuerza nuevamente las ideas de sobreprotección y especialmente de infantilización. ¿Qué puede ser más infantilizante que negar la posibilidad de ejercer los derechos sexuales y reproductivos? Esta acción por sí sola es un mecanismo de sometimiento que tiene como aliados: la sobreprotección, en forma de miedos de abusos, de sufrimiento; los tabúes, ya que en una sociedad donde los padres/madres evitarían si pudieran el ejercicio de la sexualidad de sus hijos/as sin discapacidad pueden hacerlo fácilmente en estos hijos e hijas con discapacidad; las diversas acusaciones sobre abusos sexuales en los servicios de discapacidad y las condenas mediáticas con sus consecuencias. Una trampa difícil de evitar.

¿Qué posición deben asumir las y los facilitadores? Imposible responder con una fórmula. Nuevamente la apelación será a participar del diálogo, están en la situación. Facilitar el desarrollo de la escena.

\section{Un dispositivo a medida de quién}

Nos creemos fundando un dispositivo centrado en el usuario, pero cuando el usuario no encaja en las propuestas del servicio decimos que el problema es que se nos queda por fuera del parámetro de admisión, que tenemos un proyecto institucional que se aplica a parte de la población, que "no es para acá". Esto quizás es cierto, pero muy posiblemente es solo parte de un sistema de creencias que estamos dejando atrás, y que a veces no podemos reconocer cuando lo reciclamos. ¿Por qué no somos capaces de diseñar propuestas que alojen a cada persona en forma individual, sobre todo cuando estas personas son parte de la institución desde hace tiempo?

¿Esto estaría ocurriendo solo con algunos casos?, ¿no existen dentro de la institución (cualquiera fuera) usuarios "más potables" que otros?

Y si nuestro trabajo se enfoca en aquellos usuarios no problemáticos: ¿no será que estamos invisibilizando la demanda de los más débiles?, ¿estaremos eligiendo los más dóciles para que encajen en nuestro modelo de trabajo?

Nos enfrentamos a una nueva forma de pensar: podemos expulsar a quien no encaja o podemos rediseñar para la inclusión. El tema es que quienes durante años dijimos "no es para acá", tenemos que barajar y dar de nuevo.

Estamos hablando de cómo reaccionar a las 'resistencias' que no proponen:

- Viñeta: A se lastima la mano, pero no acepta curaciones. B se preocupa, se fastidia porque A no le permite cumplir con los pasos establecidos para las curaciones. Su preocupación es legítima, pero su única posible intervención es forzar a A para que acepte la práctica o abandonar la situación porque es 'imposible' hacer algo

- ¿Por qué B no puede pensar otras formas? 
- Una posible intervención: quizás A no quiere aceptar la práctica de curado porque ha sido injuriada demasiadas veces, porque no comprende lo que va a suceder, porque anticipa dolor, porque pierde control de la situación.

- ¿Qué pasaría si se le ofrece ser protagonista? Si por ejemplo se le ofrece que agarre el botiquín, que revise y manipule los elementos, que elija de dos o tres opciones de antiséptico, indicando cual puede arder, etc.

Figura 4. Mapa conceptual de un caso en el que el usuario se hace daño y no deja que el profesional le cure, eligiendo este entre abandonar la práctica o forzarla

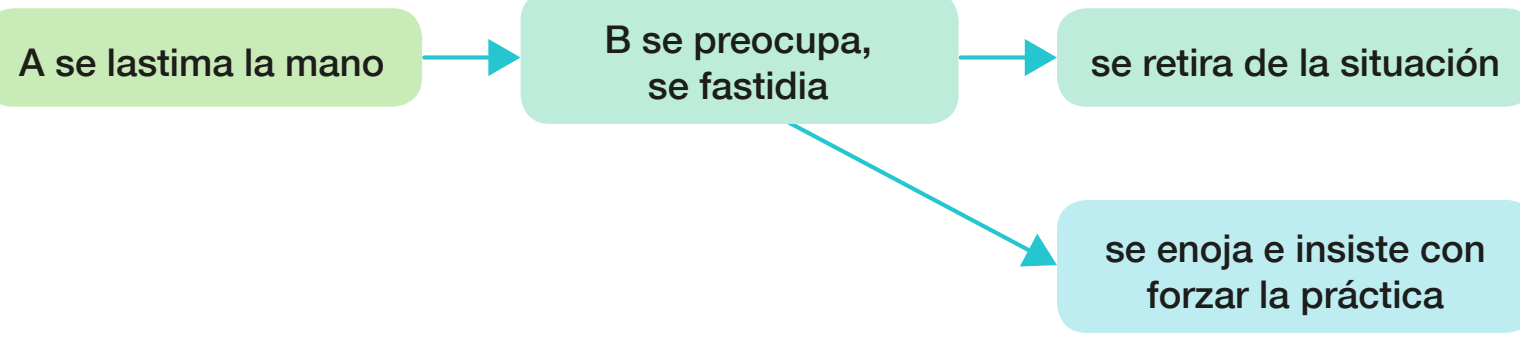

Fuente: elaboración propia.

Figura 5. Mapa conceptual de un caso en el que el usuario se hace daño y se resiste a que el profesional le cure, eligiendo este pensar diversas estrategias

A se lastima la mano $\longrightarrow \begin{gathered}\text { C lee esa resistencia } \\ \text { como un acto de } \\ \text { libertad }\end{gathered} \longrightarrow \begin{gathered}\text { Puede pensar diversas } \\ \text { estrategias }\end{gathered}$

Fuente: elaboración propia.

\section{El cuestionamiento como ejercicio}

Dice Mannoni (1982) que "la institución estallada se convierte entonces en un lugar en el que la institución, los conceptos pedagógicos, psiquiátricos... pueden ser criticados". Una institución centrada en el usuario debe practicar la crítica como un ejercicio, que no debe ser confundido con un "opinar sobre". Se observa, se interviene, se reflexiona sobre la práctica, se relee la teoría, se discute en el equipo interdisciplinario, se interviene, se observa, se reflexiona. Y así en forma constante. 
No se repiten las acciones por haber sido exitosas en el pasado. Se está siempre hoy y aquí. Y se cuestiona siempre el porqué de las prácticas.

En esta estructura, los profesionales ya no vienen como médicos, psicólogos, terapistas, sino como integrantes de un equipo que reconocen que las viejas respuestas no sirven a las nuevas preguntas. No pueden esconderse detrás del título que portan.

La formación profesional constante se convierte en un imperativo ético puesto que de lo que estamos hablando es del ejercicio de los derechos humanos más fundamentales. El usuario inmerso en un sistema de rehabilitación que no pidió ni eligió se encuentra privado de su libertad, puesto que no es capaz de decidir siquiera su no concurrencia, y está sometido a un régimen de regulación absoluta que espera su obediencia. Centrarse en el usuario, escuchar los deseos y proyectos de cada persona, poner el servicio y los profesionales a desarrollar los apoyos necesarios para que la persona alcance sus metas, requiere de profesionales permeables a cuestionar sus saberes teóricos y prácticos.

Sin dejar de lado que "centrada en el usuario", ha sido una construcción de no usuarios. Entonces intentamos estar especialmente atentos a cómo hoy los usuarios nos van mostrando sus pretensiones. Es otorgar máxima validez a la experiencia de los usuarios que se mueven en la institución en una brecha de posibilidades acotadas.

\section{El saber como forma de violencia, o no}

¿Qué dimensión ocupan "sus saberes" o "presuntos saberes"? ¿Cómo se quita ese traje tan a medida y ajustado con el uso? Este saber, ¿es saber sobre el otro?, ¿puede transformarse en conocer con el otro? El saber sobre el otro es una forma de violencia. El usuario plantea una meta, pero el profesional considera que es irrelevante o inalcanzable. Se siente en posición de juzgar la pertinencia en la vida de esa otra persona. Desestima su palabra, y en general lo justifica con las ideas de protección: para que no se frustre, porque está destinado a fracasar, porque no tiene sentido. Nuevamente aparece la sobreprotección, la seudoadultez.

¿Qué impacto tienen este tipo de intervenciones? Siguiendo a Fricker, las personas receptoras de una injusticia testimonial pueden perder confianza en su opinión o las justificaciones de la misma "de tal modo que deja de satisfacer las condiciones para el conocimiento" y si esta injusticia es un procedimiento persistente "puede perder confianza en sus propias capacidades intelectuales generales hasta el extremo de que se vea auténticamente entorpecida en su desarrollo educativo o intelectual de otra naturaleza" (Fricker, 2017: 88). Pensamos entonces que las dificultades de las personas con discapacidad intelectual para decidir sobre aspectos de sus vidas están más relacionadas con la forma de comunicación que les hemos proporcionado que con el déficit.

Quizás es claro pero sentimos que debe enfatizarse: las personas sin discapacidad no son sometidas al escrutinio, no soportan (ni resistirían) la lupa con la que se observa, juzga y evalúa a las personas identificadas como discapacitadas. 
Ponerse en el lugar del otro implica intentar comprender cómo percibe y valora esta otra persona una determinada situación y, a la vez, pensar cómo se sentiría una/o en ese lugar.

Seguimos pensando sobre la intervención profesional: "existen dos tipos de psiquiatría, la que piensa primero en la sociedad y luego en el niño, y la que hace todo lo contrario, y espera que la sociedad se adapte" (Manonni, 1982: 29) en el planteo que realizamos se busca pensar en la o el usuario en un contexto relacional.

Y frente a la necesidad de intervenir...

Axioma 1:

- Si algún asistente muestra una "conducta presuntamente inapropiada", si no sabes cómo solucionar el problema, por lo menos no lo empeores.

- El cuadro final de X llorando no es el síntoma de X, es el síntoma de la construcción conjunta de un síntoma.

En una institución basada en el usuario, el llanto de $\mathrm{X}$, la necesidad de abrazar compulsivamente de $\mathrm{Y}$, son el foco de la cuestión.

Es necesario dialogar con esa conducta y no desviar ese foco a las ideas, emociones, etc., de las y los profesionales. La dificultad de abordar la situación desde una postura relacional nos habla más del profesional que del pedido (llanto, grito, etc.) anterior. Ya que la necesidad primigenia del usuario queda invisibilizada exactamente en ese instante.

¿Cómo hace la persona con discapacidad intelectual y generalizadas necesidades de apoyo especialmente en la comunicación para poner el foco nuevamente donde lo desea/necesita/quiere?

Se necesita que varios fenómenos ocurran al mismo tiempo sin que estén imperiosamente todas las y los actores presentes físicamente. Mientras conversamos de tal o cual situación podemos tener presente simultáneamente las voces de:

- El o la profesional asistente de ese momento.

- El equipo directivo.

- La institución toda, el ecosistema inscripto en esa institución.

- Otras personas intervinientes: chóferes, cuidadores/as de sus respectivos hogares, personal de la institución (personal administrativo, de apoyo, de cocina, etc.).

- Las familias.

- Otros y otras profesionales externos a la institución (medicina, abogacía, etc.).

Debemos garantizar la inclusión de la o el usuario como sea posible. Puede estar presente físicamente, o puede estar presente con audios o videos tomados con anterioridad, o se puede preguntar: ¿qué diría su hijo/a si estuviera aquí presente presenciando esta escena familiar, o escuchando lo que se dice de él/ella? Todos y todas debemos trabajar para permitir/promocionar que la voz de la persona sea: considerada y 
validada. Si así no ocurriese (por el motivo que sea), la singularidad institucional de lo basado en el usuario podría ser una ficción, una fachada.

Solo pretendemos colaborar para mantener activa la conversación.

\author{
Todo es palabra \\ Todo es comunicación \\ Existen emociones y recursos cognitivos que \\ flotan en el ambiente todo el tiempo \\ incluso de las personas y profesionales que \\ no hacen ninguna seña, o ninguna palabra oral \\ o "creen que no la hacen"
}

Traigamos nuevamente aquello del 'capricho'. Respecto a ello se dice: "si le damos con el gusto, podemos estar fortaleciendo las conductas caprichosas". Las formas lingüísticas corresponden a la cultura y son respuesta a la cultura. Unir capricho con darle el gusto, es una construcción común de muchas familias, teorías científicas y/o saber popular. Pero la conceptualización 'capricho' es una respuesta profesional a la cultura. Suponemos que si la persona hubiera podido decir: "profe, necesito salir dos minutos al baño" (cuando en realidad quería salir a pintarse las uñas) este artículo no estaría siendo escrito ya que nada de lo que siguió después hubiera sucedido.

Se suele direccionar la palabra a la idea de inteligencia, y de inteligencia ligada al cociente intelectual. La persona que pidió "pintarse la uña, o ir al baño, o buscar papelitos para pegar con cola" si lo hiciese de un modo pertinentemente lingüístico en relación a la cultura, y específicamente a la cultura del profesional que le toque en suerte, lo instará al profesional a responder de otro modo.

Tengamos cuidado en naturalizar estos mecanismos casi invisibles a la "normalidad de la vida institucional".

La tarea es tan compleja que se necesita que quienes participan estén en estado de alerta, como flotando en el espacio institucional, atentos a las interacciones, convirtiéndose en testigo de lo que ocurre, para que una vez detectada una conversación obturada para volver a promover nuevamente otro diálogo colaborativo. Esta búsqueda de loops buscando lo dialógico es interminable. Sucede, o debería suceder, todo el tiempo.

Lo paradójico de este tipo de mirada institucional es que para que esté basada en el usuario hay que revisarse a uno mismo todo el tiempo. No existe entonces la posibilidad de hablar del "caso X" sin estar hablando de uno mismo. Y no de uno mismo a modo de confesión de sentimientos o de egocentrismo profesional, sino de ese uno en relación con el usuario/a. Contribuir al cambio pero sin evaluar o clasificar de qué tipo de cambio se trata. La responsabilidad es ya no con el resultado sino con el proceso, con la ética del trabajo.

Podemos considerarnos responsables de hacer contribuciones que posibiliten el cambio, sin enfocarse en el tipo de cambio que se produzca, cómo y cuándo suceda. No nos estaríamos orientando a los resultados sino a las otras responsabilidades éticas, como por ejemplo la de no lastimar a la gente.

¿Cómo evaluamos entonces el progreso del trabajo? Tratando de seguir la conversación segundo a segundo para observar u oír las señales que las y los usuarios dan, que dicen que las preguntas y comentarios no son 
lo suficientemente inusuales como para resultar estimulantes para ellos o que, por el contrario, son demasiado inusuales. Las y los clientes dan muchas señales y la tarea consiste en entrenar nuestra sensibilidad para poder ver $u$ oír esas señales.

La práctica de la conversación no tiene el formato: habla Él/Ella y después Yo.

Más bien es una danza, en donde no hay fichas aisladas, ni respuestas aisladas del contexto; pertenecen a ese momento. Entonces debemos estar interesados honestamente a dar respuesta al pedido previo.

En un centro de día no es una tarea sencilla ya que por lo general son las 'imágenes' las promotoras de la comunicación. Por ejemplo: $X$ se duerme, se levanta y sale para algún lugar, pide ir a un lado y se va a otro, golpea una mesa para pedir o protestar o porque sí. Suponemos que la respuesta a esa "imagen movimiento" debe tener cierta coherencia a ese tipo de pedido.

Un estilo pretendido de los profesionales que asisten a usuarios es pensar cada una de las actividades como "verdades provisorias". Tapizar una silla, desarmar un equipo de música para aprender a utilizar herramientas, curarse solo una herida, etc., son propuestas que sirven solo si le son útiles al usuario. Si en ese momento le agradan, si se ve atraído, viento en popa. Si no, tiene todo el derecho de no realizarlas. Si no, es cautivo de la tarea, del profesional y de la institución.

Y parece ser que lo más difícil de la tarea es que el profesional en cuestión esté prestando la suficiente atención a la 'conversación' que se genera en estas acciones como para poder identificar si su propuesta está siendo de utilidad.

La idea es promover la apertura de diálogos con los usuarios que son los que padecen históricamente los procedimientos infantilizantes y patologizantes.

El esfuerzo entonces es dialogar, es doblar fuerzas ya no para que haga determinada tarea sino para que esa tarea sea significativa y que tenga sentido para el usuario. El propósito es provocar la creación de "tonos de conversación y comprensión mutua de significados.

Hay que hacer un viraje que se proponga dejar de lado toda connotación positiva binaria de las conductas de los usurarios ("sos un genio", "sos maravilloso", etc.) por una escucha dialógica de lo que sucede diariamente. El carácter binario (blanco/negro, bueno/malo, correcto/incorrecto, etc.) de esas afirmaciones no es banal ya que es solo el profesional quien las nombra y el usuario quien las recibe. No solo eso sucede en ese evento, también al aceptarse este tipo de interacción como válida (muchas veces por la respuesta agradecida del usuario, por ejemplo sonriendo) anula todas las posibilidades de conductas y emociones posibles. La paleta de colores de esa conversación solo tiene dos: blanco y negro. El usuario, elija la opción que elija, queda atrapado en la telaraña de lo correcto y lo incorrecto. Tal vez luego aprenda a actuar en consecuencia no solo para congraciar al profesional sino porque careció y carece de la posibilidad de ejecutar (correcta o incorrectamente) otras acciones posibles. Preocupa entonces la potencialización de una especie de doble cárcel: las dificultades para elegir personales y ligadas a sus dificultades intelectuales más las antes descriptas. Estas últimas son menos observables que las del propio usuario, son más sutiles, ergo más peligrosas. Para desbaratar esa tela de araña invisible, promover un intercambio dialógico, constituyen un tipo de inter- 
cambio más saludable y más justo para ambas partes. Ambos (usuario y profesional) aprenden a apoyarse en lo que está ocurriendo en ese momento, y el profesional es quien confía en el punto de vista del usuario sin desechar el propio. Este encuentro (diario) es único e irrepetible para ambos y para todas y todos los demás participantes de ese intercambio. De esta forma la idea de institución centrada en el usuario deja de ser una proclama de la Convención, para ser una práctica cotidiana de sujetos de derecho ejerciendo ese derecho.

¿Cómo entonces reformulamos las instituciones para que dejen de ser instrumentos de reproducción de un sistema de exclusión para ponerse al servicio del proyecto de vida de los usuarios?

Un fenómeno poco pensado en nuestro país es quién está contratando a los profesionales: ¿quién abona los servicios brindados? Este es un fenómeno que en la particularidad del sistema de servicios de discapacidad de Argentina queda solapado por la relación de agencia que organiza esta situación: quien contrata no usa ni paga (familiar), quien usa (persona con discapacidad) no contrata ni paga, quien paga (obra social) no contrata ni usa. Esto dificulta a las y los profesionales la comprensión sobre quién es el o la cliente/a, constituyéndose en una nueva invisibilización del usuario.

Pero si la pretensión es centrarnos en quienes usan debemos pensar que cliente o clienta es la persona a la que brindamos servicios. En este nuevo contexto desestimar el llanto, menospreciar los intereses del usuario sería incompatible. Como dice el lema del famoso supermercado "Regla № 1: el cliente siempre tiene la razón".

Dice Rogers (Rogers y Wainberg, 1964): los rasgos principales de la terapia centrada en el cliente, de la cual es heredera el enfoque centrado en la persona, son la confianza radical en la persona del cliente y el rechazo al papel directivo del terapeuta. No estamos inventando nada, estamos recuperando una idea que resulta compleja en general y, específicamente referida a personas con discapacidad intelectual, casi imposible. ¿Cómo se hace para confiar en el camino que decide llevar el o la usuaria?

Cambiar la pregunta sobre cómo puedo tratar, curar o cambiar a esta persona la propuesta sería cómo crear una relación que esta persona pueda utilizar para su propio desarrollo, desechando toda idea de eficacia terapéutica (él/ella debe terminar de pintar la silla hoy porque así fue pensado el proyecto de este semestre) y cuidando el bienestar del usuario.

Y el camino que estamos proponiendo se puede simplificar en dos elementos: establecer diálogos y fomentar la toma de decisiones.

Esta fórmula se complica cuando se mira de cerca. Por un lado, establecer diálogos, pero con personas que tienen extensas o generalizadas necesidades de apoyo a la comunicación. Y fomentar la toma de decisiones en personas que no han recibido información adecuada, que tienen bajos niveles de autonomía y pocas posibilidades de expresar intereses.

El trabajo profesional entonces se reduce a encontrar esa brecha posible dentro de la cual la persona puede ejercer su autodeterminación, y asegurarse que elija el 100 por ciento de lo que queda en ese espacio. 
Figura 6. Mapa conceptual que muestra cómo convertir un centro de día como dispositivo carcelario, en el marco de una sociedad prejuiciosa y segregada, en un dispositivo que fomente la libertad y el empoderamiento

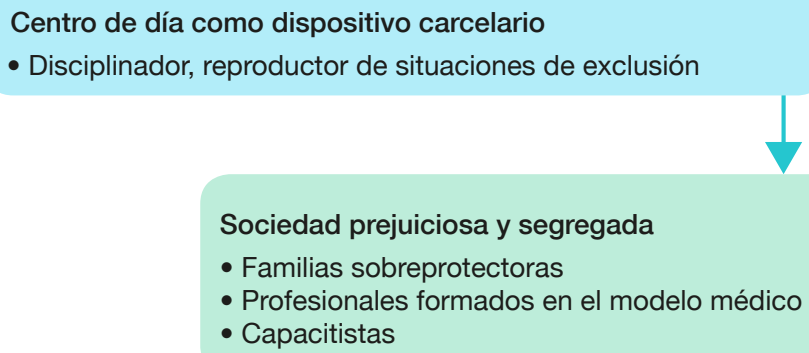

\section{Viñetas de respeto: elegir todo lo posible}

Una cuidadora acompaña a un adulto con discapacidad intelectual con generalizadas necesidades de apoyo, incluyendo la comunicación $(A)$, dentro de un sistema de vivienda convivencia y realiza diversas acciones: en un momento informal de la vida de la vivienda, le llega un mensaje de voz a su celular y ella le acerca el teléfono y le dice "escuchá... este es fulano (familiar de la cuidadora), me manda saludos". A emite un sonido gutural y ella pregunta "¿querés agua?", A asiente con la cabeza, ¿agua o jugo? repregunta. Con esa forma de escucha A pudo salir y sentarse en el parque, entrar. Cuando todos comenzaron a bañarse. A comenzó a tironear de la remera y ella preguntó "¿vos te querés bañar?", (su baño estaba previsto para la mañana, pero ella "escucha" su gesto y le ofrece la posibilidad de bañarse a la noche, cosa que la persona elije). Su accionar le permite a A elegir todo lo posible de ser elegido dentro de su brecha de autodeterminación. Cuidadora y usuario han estado danzando dialógicamente: a la cuidadora le parece bien compartir su historia personal (la llamada telefónica) y también le parece que debe cumplir con el deseo del usuario de bañarse en un horario no previsto.

\section{- Amar la trama más que el desenlace ${ }^{10}$}

Cuando estamos en el diálogo no esperamos ni buscamos resultados, sino estar en el momento, en la conversación. Proporcionarle al otro u otra una relación significativa donde, como dice Rogers (1964), com- 
prender empáticamente los sentimientos que expresan y aceptarlos. Entender que estas personas ejercen su derecho a ser diferentes y por tanto lograr que las personas desarrollen su potencial hacia un cambio positivo, constructivo, que les permita desarrollar un proyecto de vida, mejorar su socialización y hacer el pasaje de seudoadultez a adultez.

\section{- Ir y venir, seguir y guiar, dar y tener, entrar y salir de fase ${ }^{11}$}

Proponemos para nosotros y nosotras una participación encarnada, física, emocional y crítica para reconstruir, reformular y transformar las prácticas donde seamos conscientes de cómo afectamos mutuamente nuestras vidas, nuestra responsabilidad conjunta por el resultado de nuestras interacciones. Cómo el bienestar está profundamente relacionado con nuestras relaciones interpersonales, cómo lo cultural influencia nuestro mundo y cómo debemos reconocer y explorar los diversos mundos de valores encontrándonos respetuosamente en las diferencias (Gergen et al., 2009).

Ese estar en el diálogo que nos posibilite entrar en fase con el otro, sintonizar para comprenderlo y salir de fase para planificar las acciones y los apoyos que habiliten en el otro/a la posibilidad de ejercer sus derechos. Las personas con las que trabajamos no pidieron esa rehabilitación, nos bancamos, animamos, soportamos decir esto, saber que no nos eligieron y estamos dispuestos a descuartizar nuestras prácticas, para pasar de carceleros a ser partícipes de conversaciones más democráticas con las y los usuarios y entre profesionales. Para hacer un vínculo más justo, para ser facilitadores y aportar a la calidad de vida de las personas. 


\section{Referencias bibliográficas}

Andersen, T. (1993): The reflecting team: Dialogues and Dialogues About the dialogues. Nueva York: Norton.

Anderson, H. (2017): Collaborative-Dialogue Based Research as Everyday Practice: Questioning our Myths (en línea). <http://www.harleneanderson.org/articles/newbatch/Collaborative\%20Dialogue\%20Research\%20Simon\%20 Chapter.pdf>, acceso 10 de enero de 2019.

Anderson, H. y Goolishian, H. A. (1988): "Human Systems as Linguistic Systems: Preliminary and Evolving Ideas about the Implications for Clinical Theory". Family Process, 27 (4): 371-393.

Bakhtin, M. M. (1986): “Hacia una Filosofía del Acto Ético”, en Bakhtin, M. M. (1997): Hacia una Filosofía del Acto Ético, De los Borradores y Otros Escritos. Barcelona: Anthropos.

Bakhtin, M. M. (1984): Esthétique de la création verbale. París: Gallimard.

Bakhtin, M. M. (1981): The dialogic imagination: Four essays by M. M. Bakhtin. Austin: University of Texas Press.

Brea et al. (2017): "Del dicho al hecho: hacia un centro de día centrado en las personas". Conferencia presentada en las XII Jornadas Sociología UBA. Universidad de Buenos Aires, Argentina (en línea). <https://docs.google. com/document/d/17CviHosG2GOFVpvULjtmqqig6vs_MxgsLnbslYmBzpl/edit?usp=sharing>, acceso 10 de enero de 2019.

Brea et al. (2016): "Hacia una institución centrada en la persona". Conferencia presentada en las IV Jornadas Nacionales Discapacidad y Derechos. Universidad de Buenos Aires, Argentina (en línea). <https://docs.google. com/document/d/1aOtCcY1gLLODxNo1VgvssIBW4Go_LbiocxoglmnC5lk/edit?usp=sharing>, acceso 10 de enero de 2019.

Cardona, M. C. (2006): Diversidad y educación inclusiva. Madrid: Pearson-Educación.

Diez, M. L. (2017): La muerte como freno hacia la plena inclusión de las personas con diversidad funcional intelectual (Trabajo de Fin de Grado). Universidad de Valladolid, España (en línea). <http://uvadoc.uva.es/handle/10324/26707>, acceso 10 de enero de 2019.

Foucault, M. (2007): Historia de la sexualidad. 1. La voluntad de saber (Teoría). Madrid: Siglo XXI.

Foucault, M. (1976): "Curso del 7 de enero de 1976" y "curso del 14 de enero de 1976", en Foucault, M. (1992): Microfísica del poder. Madrid: La Piqueta.

Fricker, M. (2017): Injusticia epistémica. El poder y la ética del conocimiento. Barcelona: Herder Editorial.

Gergen, K. et al. (2009): Constructing worlds together. Boston: Pearson Allyn \& Bacon.

Ghiso, A. M. (2009): "Investigación dialógica, resistencia al pensamiento único". Maestros y maestras gestores de nuevos caminos. Educación, conocimiento y poder, 50: 12-27.

Mannoni, M. (1982): Un lugar para vivir. Barcelona: Editorial Crítica.

Montobbio, E. (1995): La identidad difícil: el falso YO en la persona con discapacidad psíquica. Barcelona: Masson.

Naciones Unidas (2006): Convención sobre los Derechos de las Personas con Discapacidad. Nueva York: ONU.

Palacios, A. (2008): El modelo social de discapacidad: orígenes, caracterización y plasmación en la Convención Internacional sobre los Derechos de las Personas con Discapacidad. Madrid: Cinca. 
Pakman, M. (2014): Texturas de la imaginación. Barcelona: Gedisa.

Pakman, M. (2010): Palabras que permanecen, palabras por venir. Barcelona: Gedisa.

Rogers, C. y Wainberg, L. (1964): El proceso de convertirse en persona. México: Paidós.

Shotter, J. (1993): Realidades Conversacionales. Buenos Aires: Amorrortu.

Valencia, G. C. (2016): "Investigar desde América Latina y sobre América Latina, lo que nombra el nombre”. Revista Latinoamericana de Metodología de las Ciencias Sociales, 6 (1): e001 (en línea). <http://www.memoria.fahce. unlp.edu.ar/art_revistas/pr.7313/pr.7313.pdf>, acceso 10 de enero de 2019.

Verdugo, M. A. (2009): Cómo mejorar la calidad de vida de las personas con discapacidad. Salamanca: Amarú.

Veyne, P. (2014): Foucault: pensamiento y vida - $1^{\circ}$ edición. Buenos Aires: Paidós.

Wittgenstein, L. (1953): Philosophical Investigations. Oxford: Blackwell. 